\title{
Cost-effectiveness of different human papillomavirus vaccines in Singapore
}

Vernon J Lee ${ }^{1,2^{*}}$, Sun Kuie Tay ${ }^{3}$, Yee Leong Teoh ${ }^{4}$ and Mei Yin Tok ${ }^{1}$

\begin{abstract}
Background: Human papillomavirus (HPV) vaccines are widely available and there have been studies exploring their potential clinical impact and cost-effectiveness. However, few studies have compared the cost-effectiveness among the 2 main vaccines available - a bivalent vaccine against HPV 16/18, and a quadrivalent vaccine against 6/ 11/16/18. We explore the cost-effectiveness of these two HPV vaccines in tropical Singapore.

Methods: We developed a Markov state-transition model to represent the natural history of cervical cancer to predict HPV infection, cancer incidence, mortality, and costs. Cytologic screening and treatment of different outcomes of HPV infection were incorporated. Vaccination was provided to a cohort of 12-year old females in Singapore, followed up until death. Based on available vaccines on the market, the bivalent vaccine had increased effectiveness against a wider range of HPV types, while the quadrivalent vaccine had effectiveness against genital warts. Incremental cost-effectiveness ratios (ICER) compared vaccination to no-vaccination, and between the two vaccines. Sensitivity analyses explored differences in vaccine effectiveness and uptake, and other key input parameters.

Results: For the no vaccination scenario, 229 cervical cancer cases occurred over the cohort's lifetime. The total discounted cost per individual due to HPV infection was SGD\$275 with 28.54 discounted life-years. With 100\% vaccine coverage, the quadrivalent vaccine reduced cancers by 176, and had an ICER of SGD\$12,866 per life-year saved. For the bivalent vaccine, 197 cancers were prevented with an ICER of $\$ 12,827$ per life-year saved. Comparing the bivalent to the quadrivalent vaccine, the ICER was $\$ 12,488$ per life-year saved. However, the cost per QALY saved for the quadrivalent vaccine compared to no vaccine was $\$ 9,071$, while it was $\$ 10,392$ for the bivalent vaccine, with the quadrivalent vaccine dominating the bivalent vaccine due to the additional QALY effect from reduction in genital warts. The overall outcomes were most sensitive to vaccine cost and coverage.
\end{abstract}

Conclusion: HPV vaccination is a cost-effective strategy, and should be considered a possible strategy to reduce the impact of HPV infection.

Keywords: Cervical cancer cervical intraepithelial neoplasia, incremental cost effectiveness ratio, vaccine

\section{Background}

Cervical cancer is the second most common cancer in women worldwide [1], affecting 500,000 women annually and resulting in more than 250,000 deaths [2]. In Singapore, despite decreasing incidence of cervical cancer as a result of regular cytological screening, it remains a common gynaecological cancer [3], with 200 cases and about 100 deaths annually $[3,4]$.

\footnotetext{
* Correspondence: vernonljm@hotmail.com

${ }^{1}$ Center for Health Services Research, National University of Singapore, Singapore

Full list of author information is available at the end of the article
}

Human papillomavirus (HPV) infection is the main cause of cervical cancer. There are more than 150 different strains of HPV but only about 15 are high-risk oncogenic strains for cervical cancer. Of these, HPV types 16 and 18 account for about $70 \%$ of all cervical cancer cases, while the other oncogenic strains account for the rest [5-7]. Two prophylactic HPV vaccines, a bivalent vaccine which targets HPV 16/18, and a quadrivalent vaccine which targets $6 / 11 / 16 / 18$, are widely available. Both vaccines have shown to be highly effective in clinical trials and economic studies of HPV vaccines have found them to be cost-effective in various
C Biomed Central

() 2011 Lee et al; licensee BioMed Central Ltd. This is an Open Access article distributed under the terms of the Creative Commons Attribution License (http://creativecommons.org/licenses/by/2.0), which permits unrestricted use, distribution, and reproduction in any medium, provided the original work is properly cited. 
countries [8]. As such, many countries are considering universal vaccination of women with the HPV vaccine.

Before any universal vaccine implementation, it is important for policymakers to understand the long-term benefits (beyond the time horizon of clinical trials) of the vaccine by using mathematical modelling in a decision-analytic framework [9-17]. Extending previous studies of HPV vaccination, we compare the status quo of cervical cancer screening only and vaccination with a quadrivalent or bivalent vaccine in addition to baseline screening. This allowed us to determine the cost-effectiveness of vaccination over the current screening practices, and the incremental cost-effectiveness of one vaccine over the other.

\section{Methods}

We developed a deterministic Markov state-transition model based on the natural history of HPV infection and cervical cancer in the tropical South-East Asian city-state Singapore (Figures 1). We assumed that the natural history is relatively long, therefore the cycles were annual $[18,19]$. The model was performed on a hypothetical cohort of women in Singapore who turned 12 years old in 2008, which is the typical age of HPV vaccination. This amounted to a mid-year female population of 25,000 [20] and the model followed this cohort until death - 88 cycles, assumed to correspond to the time needed until everyone has died. We assumed that sexual activity and hence HPV infection only occurred after age 12 .

Life expectancies and annual mortality rates for the cohort were obtained from the Singapore Department of

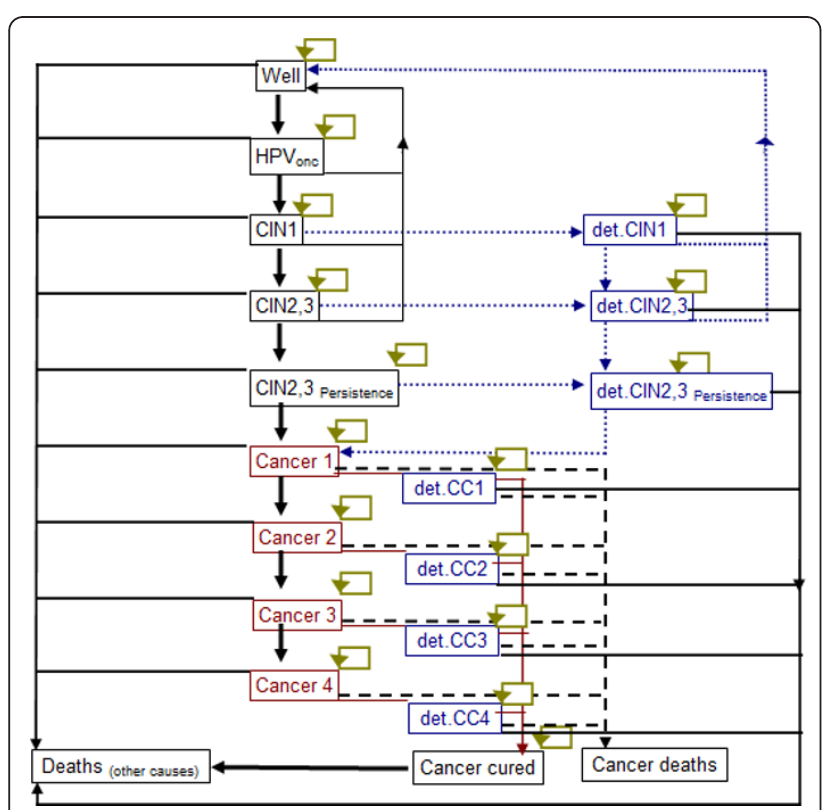

Figure 1 Markov model for the history of cervical cancer
Statistics [20]. For the input variables (Table 1) [4,18-29], we obtained data from local sources where available, including disease incidence and costs of interventions and outcomes. Most studies on disease evolution and transition between different disease states were performed by a few large international studies - we therefore relied on these to obtain input parameters. The variables were calibrated to the local setting based on local incidence data.

\section{Transition probabilities}

HPV infection progresses to cervical intraepithelial neoplasia (CIN), the precursor of cervical cancer. The usual progression is from CIN 1 to $\mathrm{CIN} 2, \mathrm{CIN} 3$, and persistent forms of the latter 2 CIN stages. CIN 2,3 is grouped together due to similar outcomes and management, while the persistent forms are direct precursors of cervical cancer. Cervical cancers are divided into 4 prognostic stages 1 to 4 . Each progressive stage is associated with poorer prognosis, lower treatment success rates, and higher recurrence and relapse rates. The transition probabilities for disease progression were obtained from previously published sources (Table 1 ). To account for uncertainty, we performed wide sensitivity analyses.

\section{Screening}

In Singapore, recommended screening for cervical cancer starts at age 25 years for women who have ever had sexual intercourse and at 3 yearly intervals if previous smears were negative, until the age of 69 if all smears are negative. In 2004, a survey showed that across all age groups, only $52 \%$ of women had their Pap smear done in the last 3 years, but most women did not undergo regular screening every 3 years [4]. We therefore assumed that Singaporean women would on average start screening at 25 years of age, and $17 \%$ of the cohort would undergo screening each year.

We assumed that the sensitivity of PAP smears were $58 \%$ for CIN 1 and $61 \%$ for CIN2,3 [30,31]. If a smear is abnormal, further tests including colposcopy and if necessary biopsy are introduced as per local abnormal pap smear guidelines [41], and treatment performed as clinically indicated. We also assumed that once positive, all CIN states would be confirmed by colposcopy and biopsy, and $75 \%$ of CIN1 and $75 \%$ of CIN2, 3 cases would comply to treatment with an efficacy of $90 \%$ [32].

\section{Treatment}

For CIN, the chance of cure is almost $100 \%$ and we assumed a mean cost of treatment for the various CIN stages. For cervical cancer, the chance of cure depends on the cancer stage, while the treatment cost depends on the treatment type. We also determined the chance of symptoms occurring which would lead to early 
Table 1 Vaccination, screening, cost parameters and transition probabilities

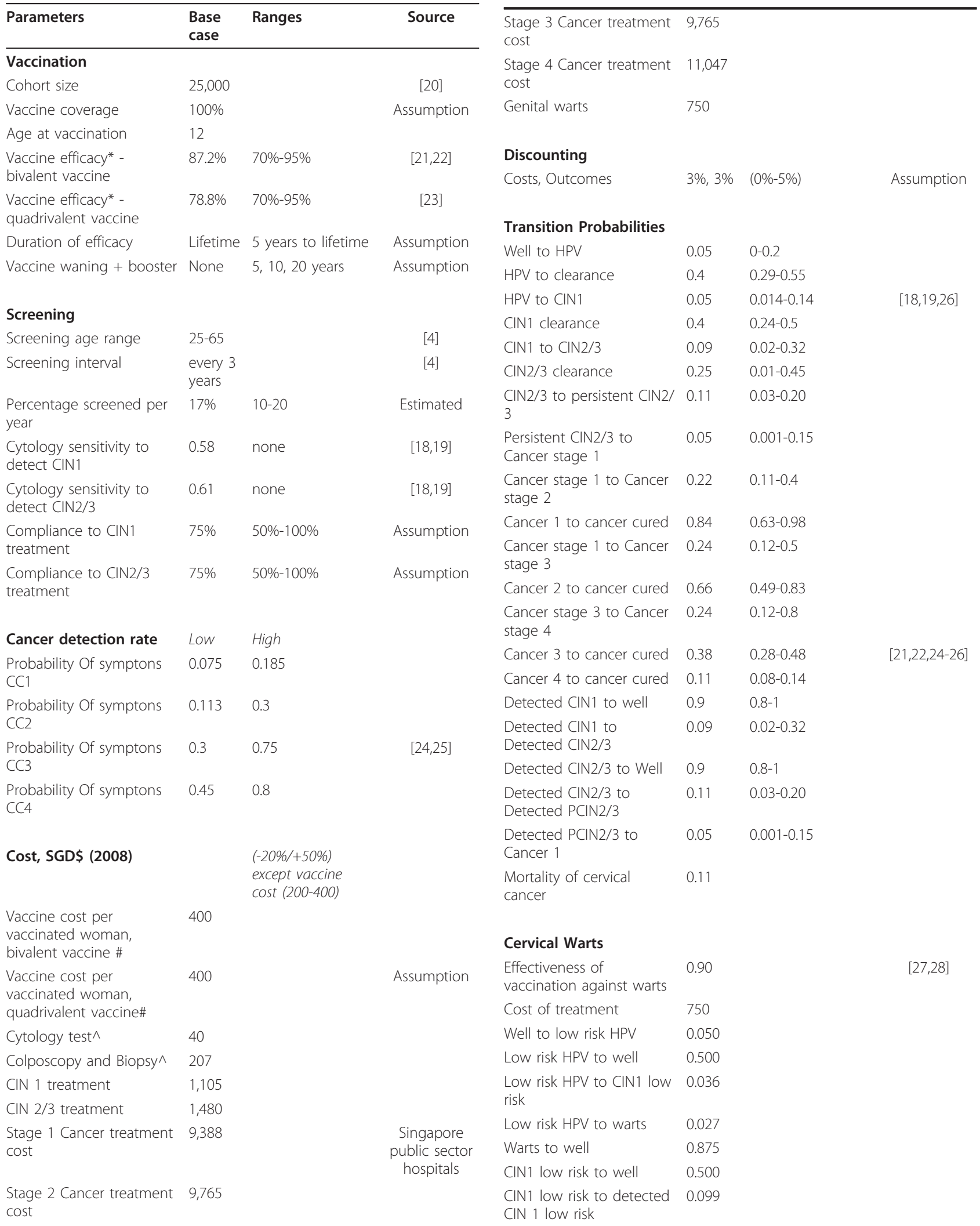

Table 1 Vaccination, screening, cost parameters and transition probabilities (Continued)

Stage 3 Cancer treatment 9,765

Stage 4 Cancer treatment $\quad 11,047$

cost

\section{Discounting}

Transition Probabilities

\section{Cervical Warts}

vaccination against warts 
Table 1 Vaccination, screening, cost parameters and transition probabilities (Continued)

Detected CIN 1 low risk 0.950

to well

QALYs

Disease free 1

$\begin{array}{llll}\text { Genital warts } & 0.96 & 0.91-0.99 & {[10,25,29]}\end{array}$

$\begin{array}{lll}\text { Detected CIN } & 0.89 & 0.84-0.94\end{array}$

Cancer detected

Stage I $\quad 0.65 \quad 0.49-0.81$

Stage $\| \quad 0.56 \quad 0.42-0.70$

Stage III $\quad 0.56 \quad 0.42-0.70$

Stage IV $\quad 0.48 \quad 0.36-0.60$

Cancer cured

0.94

*Calculated, refer to Table $1 \mathrm{~b}$.

\#including costs of implementing, administration and support for vaccination programme

^including admininistrative cost \& patient costs

detection and treatment. We modeled these outcomes and costs based on local data obtained from hospitals. As local data on survival rates together with disease transition probabilities were not available, and overall survival rates in Singapore were comparable to developed countries [42], we used available cancer survival rates from similar developed countries [21,22]. These survival rates were annualized across 5 years to determine overall cure rates for each year - we assumed that those who survive beyond 5 years were cured. Once cancer was detected, we assumed that all individuals would undergo treatment. We did not model outcomes of treatment as individual state transitions but attributed an overall cost to each state.

\section{Vaccination}

In Singapore, the quadrivalent and bivalent vaccines have been licensed since 2006 and 2007 respectively. Vaccination remains voluntary, and privately funded individually. To compare between the vaccines, we assumed that the bivalent vaccine has a higher efficacy against other non-16/18 high-risk HPV types compared with the quadrivalent vaccine [32] using a technique described by Debicki et al [25] and shown in Table 2 . However, the quadrivalent vaccine has additional protection against other low-risk HPV-types that cause genital warts and CIN 1 - the bivalent vaccine is assumed to have no such protection.

Based on recent studies, the range of protection for non-16/18 oncogenic HPV types are between $53.0 \%$ and $68.2 \%$ for the bivalent vaccine $[23,33]$ and $32.5 \%$ for the quadrivalent vaccine [21]. The overall effectiveness for the quadrivalent vaccine has been shown to be about $75 \%$ [34]. In addition, the quadrivalent vaccine has a
90\% protection against HPV-types that cause genital warts $[27,28]$

Base case vaccine characteristics are assumed as follows: (1) proportion of individuals protected following immunization is $100 \%$; (2) vaccine duration is life-long; (3) effectiveness of both vaccines against HPV types 16/ 18 are similar at $95 \%[23,33-40]$; (4) to create fair competition, we assumed that the prices of both vaccines were equivalent and includes all vaccination costs; (5) we did not include therapeutic benefits to vaccinated patients already infected and assumed that the natural disease history is unaltered; (6) we assumed that all girls based on the coverage rate would receive the full vaccine course and be immunized after 1 year. We performed sensitivity analyses on these assumptions.

\section{CIN State Adjustments}

For the CIN states, we had to determine the actual proportion of CIN cases that are reduced by vaccination, as not all CIN states are affected by vaccination as compared to cancer. This is to allow for the reduction proportion to be accurate as this will influence the costs of the different strategies. We used a correction method well described by Debicki et al [25] where we determined the proportion of CIN 1 and CIN2/3 cases that were caused by non-oncogenic viruses in the no vaccine strategy, and added these numbers to those obtained for oncogenic viruses in the vaccination strategy (Table 2).

\section{Genital Warts}

Genital warts are another manifestation of HPV infection caused by non-oncogenic HPV viruses. Low-oncogenic-risk HPV-6/11 is responsible for $>95 \%$ percent of genital warts $[43,44]$. Genital warts cause superficial symptoms but do not result in cancer, and are therefore a separate outcome of HPV infection.

The model for the development of genital warts is shown in Figure 2. We assumed that low-oncogenic-risk HPV types can either cause clinical genital warts or CIN 1. Clinical genital warts would be identified clinically and treated. CIN 1 would be detected through the normal screening process and we assumed would be indistinguishable from CIN 1 caused by oncogenic types. A reduction in CIN 1 caused by low-oncogenic-risk HPV types would contribute to the overall reduction in CIN 1 incidence [45].

\section{Costs, Utility, and discounting}

Costs of the various interventions and outcomes were obtained from patients with HPV infection, CIN states, and cervical cancer diagnosed in 2004 across public sector hospitals in Singapore (SK Tay, unpublished data). All medical services were traced and costs collected from hospital finance data for the following 5 years or 
Table 2 Details of efficacy calculations

\begin{tabular}{|c|c|c|c|}
\hline & & & Source \\
\hline & $\begin{array}{l}\text { Bivalent } \\
\text { vaccine }\end{array}$ & $\begin{array}{l}\text { Quadrivalent } \\
\text { vaccine }\end{array}$ & \\
\hline \multicolumn{4}{|l|}{$\begin{array}{l}\text { Reduction in the } \\
\text { probability of HPV infection }\end{array}$} \\
\hline $\begin{array}{l}\text { Assumed proportion of HPV } \\
16 / 18 \text { in cervical cancer, A }\end{array}$ & $74.9 \%$ & $74.9 \%$ & {$[7]$} \\
\hline $\begin{array}{l}\text { Vaccine efficacy-percent } \\
\text { reduction in HPV 16/18 } \\
\text { persistent infections, B }\end{array}$ & $95.0 \%$ & $95.0 \%$ & {$[23,27,28,32-40]$} \\
\hline $\begin{array}{l}\text { Assumed proportion of other } \\
\text { high risk HPV in cervical } \\
\text { cancer, C }\end{array}$ & $23.4 \%$ & $23.4 \%$ & {$[7]$} \\
\hline $\begin{array}{l}\text { Vaccine efficacy-percent } \\
\text { reduction in other high risk } \\
\text { HPV persistent infections, D }\end{array}$ & $68.4 \%$ & $32.5 \%$ & {$[30-32]$} \\
\hline $\begin{array}{l}\text { Calculated reduction in the } \\
\text { probability of HPV infection } \\
(A \times B)+(C \times D)\end{array}$ & $87.2 \%$ & $78.8 \%$ & \\
\hline \multicolumn{4}{|l|}{ Corection factor for CIN1 } \\
\hline $\begin{array}{l}\text { Percent of HPV } 1618 \text { in CIN1 } \\
\text { cases which are caused by } \\
\text { oncogenic HPV, E }\end{array}$ & $37.0 \%$ & & \\
\hline Correction factor for CIN1, A-E & $37.9 \%$ & & \\
\hline \multicolumn{4}{|l|}{ Corection factor for $\mathrm{CIN} 2 / 3$} \\
\hline $\begin{array}{l}\text { Percent of HPV } 1618 \text { in CIN2/ } \\
3 \text { cases which are caused by } \\
\text { oncogenic HPV, F }\end{array}$ & $52.0 \%$ & & \\
\hline $\begin{array}{l}\text { Correction } \\
\text { factor for CIN2/3 A-F }\end{array}$ & $22.9 \%$ & & \\
\hline
\end{tabular}

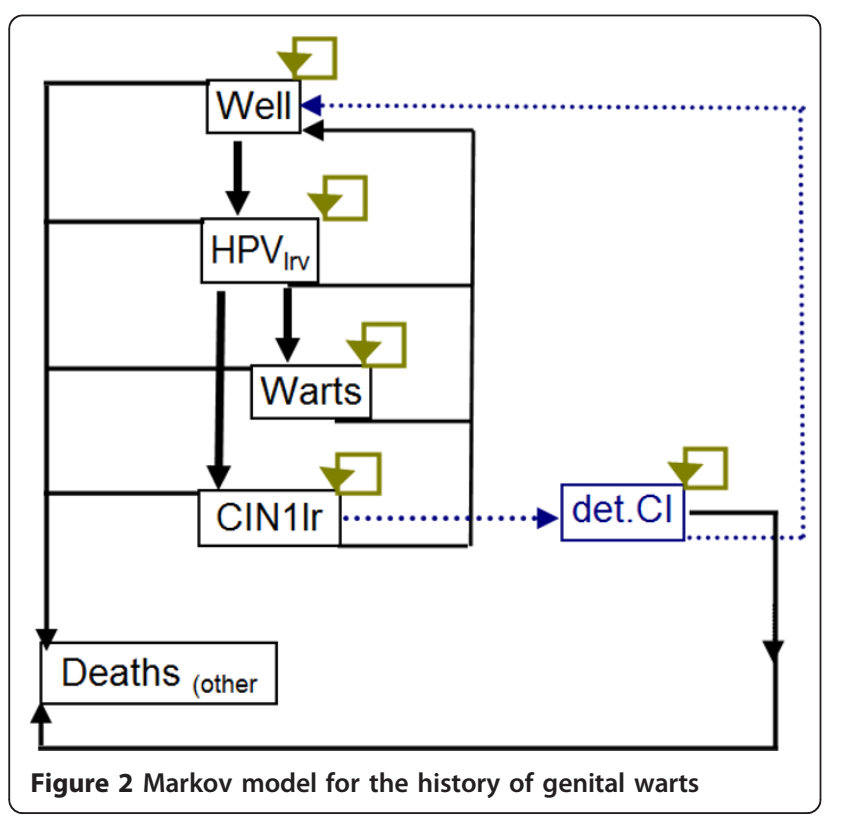

until death, and averaged across all patients. We performed the analysis starting from the year 2008 and all interventions according to technology available in 2008. We adopted the health services perspective and included all direct medical costs and benefits. Vaccination cost includes the vaccine cost and related administrative fees. All costs are represented in 2008 Singapore dollars (2008 exchange rate, USD1: SGD1.416).

For the Quality-Adjusted Life Years (QALYs) calculations, the utility values were obtained from other developed countries as similar data was not available locally (Table 1a). Utility for each health state, which ranged from 1 which corresponded to complete health to 0 for death, were multiplied by the time spent in each state. Genital warts and detected CIN (colposcopy treatment) was given utility values of 0.96 and 0.89 respectively [29]. Quality values for various detected cancer stages differed depending on the cancer stage, while cured cancer was slightly less than complete health $[10,25]$.

Since the model ran over a long time-frame, costs and benefits were translated into present values using a discount factor [46-49]. Health outcomes and costs were discounted at $3 \%$ per annum, similar to previous local economic evaluations.

\section{Analyses}

The model was run using Excel spreadsheets (Microsoft Corp, Redmond, WA) and @Risk (Palisade, Newfield, NY) simulation add-in. We performed cost-benefit analysis using the costs per life-year saved with individual economic value calculated from the net present value of future annual earnings (earnings-equivalent for the elderly), adjusted for age [50]. We also performed costeffectiveness analyses; and cost-utility analyses as not all negative health outcomes resulted in death. The incremental cost-effectiveness ratio (ICER) would be acceptable if it is below the per-capita gross domestic product (GDP) for the population. The per-capita GDP for Singapore in 2008 was $\$ 53,192$.

All parameters were subject to sensitivity analysis to determine which input variables were most important in determining the final strategy. We performed one-way and two-way sensitivity analyses on vaccination and transition parameters to determine the impact of changes in input variables. This allowed us to determine which parameters had the highest influence on the outcome, and would be priority areas for intervention.

\section{Results}

\section{Base case analysis}

Table 3 reports the base-case results of estimated cases, non-discounted and discounted total costs, life-years, and QALYs. The model estimates that approximately $86 \%$ of cervical cancer, $86 \%$ of deaths from cancer, and 
Table 3 Summary of estimated cases, non-discounted and discounted total costs and life-years of a single age-cohort ( $n=25,000)$ of 12 year old girls

\begin{tabular}{|c|c|c|c|c|}
\hline & & Screening only & Bivalent* & Quadrivalent* \\
\hline \multicolumn{5}{|l|}{ Cases } \\
\hline & Cervical cancer & 229 & 32 & 53 \\
\hline & Deaths from cervical cancer & 144 & 20 & 33 \\
\hline & CIN Persistent 2n3 detected & 2,073 & 294 & 480 \\
\hline & CIN 2n3 detected & 382 & 135 & 168 \\
\hline & CIN 1 detected & 2,109 & 1,127 & 1,293 \\
\hline & Genital warts & 4,126 & 4,126 & 447 \\
\hline \multicolumn{5}{|c|}{ NON-DISCOUNTED } \\
\hline \multirow[t]{8}{*}{ Total costs } & & $21,150,496$ & $25,020,340$ & $22,822,396$ \\
\hline & Vaccine costs & - & $10,000,000$ & $10,000,000$ \\
\hline & Screening costs & $11,006,014$ & $9,949,324$ & $10,078,234$ \\
\hline & CIN1 treatment costs & $2,330,522$ & $1,245,203$ & $1,292,796$ \\
\hline & CIN $2 \& 3$ treatment costs & 564,776 & 199,475 & 247,908 \\
\hline & CIN Persistent 2 \& 3 treatment costs & $3,067,301$ & 435,141 & 710,367 \\
\hline & Genital warts treatment costs & $3,094,714$ & $3,094,714$ & 335,580 \\
\hline & Cervical cancer treatment costs & $1,087,169$ & 96,483 & 157,511 \\
\hline Life-years (LY) & & $1,692,651$ & $1,695,651$ & $1,695,338$ \\
\hline QALYS & & $1,717,089$ & $1,720,571$ & $1,720,299$ \\
\hline \multicolumn{5}{|l|}{ DISCOUNTED } \\
\hline Total costs & & $6,880,106$ & $15,034,926$ & $14,210,399$ \\
\hline Life-years (LY) & & 711,164 & 711,800 & 711,734 \\
\hline QALYS & & 735,991 & 736,775 & 736,784 \\
\hline
\end{tabular}

*In addition to screening

$47 \%$ of CIN $1,65 \%$ of CIN $2 / 3$, and $86 \%$ of persistent CIN $2 / 3$ cases could be prevented by the bivalent vaccine vaccination. The quadrivalent vaccine avoids these cases by $2-9 \%$ less than the bivalent vaccine. However, the quadrivalent vaccine reduces genital warts cases by $89 \%$. Vaccination with the bivalent or quadrivalent vaccine yielded 634 and 570 respectively more life years than screening alone.

From the cost-benefit analysis, the incremental savings is $\$ 8.23 \mathrm{~m}$ with the quadrivalent vaccine and $\$ 9.47 \mathrm{~m}$ with the bivalent vaccine, or an advantage of $\$ 1.24 \mathrm{~m}$ for the bivalent over the quadrivalent vaccine. For the cost-effectiveness analysis, the cost per life year saved for the quadrivalent vaccine compared to no vaccine was $\$ 12,866$, compared to $\$ 12,827$ for the bivalent vaccine. Comparing the bivalent to the quadrivalent vaccine, the ICER is $\$ 12,488$, showing that the bivalent vaccine saves more lives for the cost. However, the cost per QALY saved for the quadrivalent vaccine compared to no vaccine was $\$ 9,071$, while it was $\$ 10,392$ for the bivalent vaccine, with the quadrivalent vaccine dominating the bivalent vaccine due to the additional QALY effect from reduction in genital warts.

\section{Sensitivity analysis}

For the sensitivity analyses, we compared 3 different outcomes - the quadrivalent vaccine to screening alone, the bivalent vaccine to screening alone and the bivalent vaccine to the quadrivalent vaccine. Table 4 shows selected sensitivity analyses results. Decreasing vaccine coverage while keeping vaccination costs constant (assuming that vaccine purchases are sunk costs) increased the ICER and decreases cost-benefit across the board, especially at vaccine coverage levels $\leq 40 \%$ where vaccination is not cost-effective. If vaccination costs can be capped to only those who receive vaccination, then either vaccine remains cost effective even at $20 \%$ vaccination levels.

Lowering the overall vaccine efficacy increases ICER and decreases cost-benefit for both vaccination strategies compared to no vaccination, but vaccination still remains cost-effective even if no cross-reactivity against low-risk HPV types is present. In the latter scenario, the quadrivalent vaccine dominates the bivalent vaccine even for the additional cost per life year saved, due to the additional reduction on genital warts.

Decreasing vaccination costs for both vaccines decreases the overall ICER and increases the cost-benefit 
Table 4 Sensitivity analysis for the imput parameters on ICER and Cost-Benefit

\begin{tabular}{|c|c|c|c|c|c|c|c|c|c|}
\hline \multirow[t]{2}{*}{ Parameters } & \multicolumn{3}{|c|}{ ICER (SGD/LY saved), discounted } & \multicolumn{3}{|c|}{ ICER (SGD/QALY saved), discounted } & \multicolumn{3}{|c|}{$\begin{array}{l}\text { Cost Benefit Analysis (million SGD), } \\
\text { discounted }\end{array}$} \\
\hline & $\begin{array}{l}\text { Quadrivalent } \\
\text { vaccine vs } \\
\text { No vaccine }\end{array}$ & $\begin{array}{l}\text { Bivalent } \\
\text { vaccine } \\
\text { vs No } \\
\text { vaccine }\end{array}$ & $\begin{array}{l}\text { Bivalent } \\
\text { vaccine vs } \\
\text { Quadrivalent } \\
\text { vaccine }\end{array}$ & $\begin{array}{l}\text { Quadrivalent } \\
\text { vaccine vs } \\
\text { No vaccine }\end{array}$ & $\begin{array}{l}\text { Bivalent } \\
\text { vaccine } \\
\text { vs No } \\
\text { vaccine }\end{array}$ & $\begin{array}{l}\text { Bivalent } \\
\text { vaccine vs } \\
\text { Quadrivalent } \\
\text { vaccine }\end{array}$ & $\begin{array}{l}\text { Quadrivalent } \\
\text { vaccine vs } \\
\text { No vaccine }\end{array}$ & $\begin{array}{l}\text { Bivalent } \\
\text { vaccine } \\
\text { vs No } \\
\text { vaccine }\end{array}$ & $\begin{array}{l}\text { Bivalent } \\
\text { vaccine vs } \\
\text { Quadrivalent } \\
\text { vaccine }\end{array}$ \\
\hline tase case & 12,866 & 12,827 & 12,488 & 9,071 & 10,392 & Dom & 8.23 & 9.47 & 1.24 \\
\hline
\end{tabular}

Vaccine coverage (base:100\%) - assuming vaccine purchase costs for the cohort are sunk costs

$\begin{array}{llllllllll}20 \% & 86,397 & 83,454 & 56,178 & 61,804 & 67,631 & \text { Dom } & -6.25 & -6.57 & -0.33 \\ 40 \% & 40,444 & 39,322 & 29,109 & 28,847 & 31,864 & \text { Dom } & -2.72 & -2.75 & -0.03 \\ 60 \% & 25,124 & 24,607 & 19,981 & 17,861 & 19,938 & \text { Dom } & 0.92 & 1.21 & 0.29 \\ 80 \% & 17,464 & 17,246 & 15,337 & 12,367 & 13,973 & \text { Dom } & 4.67 & 5.23 & 0.63\end{array}$

Vaccine coverage (base:100\%) - assuming vaccine costs are as consumed

$\begin{array}{llllllllll}20 \% & 11,524 & 15,873 & 56,178 & 8,059 & 12,818 & \text { Dom } & 1.75 & 1.43 & -0.33 \\ 40 \% & 12,804 & 14,417 & 29,109 & 9,010 & 11,668 & \text { Dom } & 3.38 & 3.25 & -0.03 \\ 60 \% & 13,034 & 13,733 & 19,981 & 9,166 & 10,727 & \text { Dom } & 4,92 & 5.21 & 0.29 \\ 80 \% & 13,003 & 13,241 & 15,337 & 9,185 & 11,122 & \text { Dom } & 6,67 & 7.3 & 0.63\end{array}$

Vaccine efficacy (Bivalent base: $88.3 \%$, Quadrivalent base: 79.4\%)

\begin{tabular}{|c|c|c|c|c|c|c|c|c|}
\hline $70 \%$ & 15,008 & 17,237 & Dom & 10,369 & 13,894 & Dom & 6.43 & 5.31 \\
\hline $90 \%$ & 10,863 & 12,326 & Dom & 7,733 & 9,932 & Dom & 11.13 & 10.17 \\
\hline
\end{tabular}

Vaccination costs (base: SGD\$400 for both)

\begin{tabular}{|c|c|c|c|c|c|c|c|c|}
\hline $\begin{array}{l}\text { Decrease } \\
\text { to SGD } \\
\$ 300 \text { for } \\
\text { both }\end{array}$ & 8,521 & 8,942 & 12,572 & 5,922 & 7,205 & Dom & 10.96 & 11.96 \\
\hline $\begin{array}{l}\text { Decrease } \\
\text { to SGD } \\
\$ 200 \text { for } \\
\text { both, }\end{array}$ & 4,109 & 4,988 & 12,572 & 2,775 & 4,019 & Dom & 13.46 & 14.46 \\
\hline $\begin{array}{l}\text { Decrease } \\
\text { to SGD } \\
\$ 100 \text { for } \\
\text { both }\end{array}$ & Dom & 1,034 & 12,572 & Dom & 833 & Dom & 15.96 & 16.96 \\
\hline
\end{tabular}

Booster (base: none)

$\begin{array}{llllllllll}5 \text { years } & 91,149 & 83,707 & 19,486 & 67,830 & 70,487 & \text { Dom } & -36.07 & -35.52 & 0.54 \\ 10 \text { years } & 47,045 & 43,778 & 15,584 & 36,192 & 38,134 & \text { Dom } & -10.94 & -10.14 & 0.8 \\ 20 \text { years } & 27,321 & 26,048 & 15,067 & 19,483 & 21,093 & \text { Dom } & 0.3 & 1.13 & 0.84\end{array}$

Screening coverage rate (base: 17\%)

\begin{tabular}{|c|c|c|c|c|c|c|c|c|c|}
\hline $10 \%$ & 12,424 & 12,398 & 12,171 & 9,120 & 10,409 & Dom & 9.2 & 10.29 & 1.08 \\
\hline $25 \%$ & 13,670 & 13,558 & 12,593 & 9,199 & 10,552 & Dom & 7.68 & 8.63 & 0.95 \\
\hline $40 \%$ & 15,200 & 14,845 & 11,783 & 9,628 & 10,977 & Dom & 6.43 & 7.35 & 0.92 \\
\hline \multicolumn{10}{|c|}{ ectiveness against viral warts } \\
\hline $70 \%$ & 13,348 & 12,827 & 8,996 & 9,665 & 10,392 & 57,447 & 8.23 & 9.46 & 1.23 \\
\hline $80 \%$ & 13,143 & 12,827 & 10,768 & 9,366 & 10,392 & 640,633 & 8.35 & 9.46 & 1.11 \\
\hline $100 \%$ & 12,721 & 12,827 & 14,408 & 8,777 & 10,392 & Dom & 8.59 & 9.46 & 0.86 \\
\hline
\end{tabular}

Dom $=$ Dominated by quadrivalent vaccine 
of the vaccination strategy. Conversely, overall ICER for all comparisons increases and cost-benefit decreases when vaccine waning and administering a booster in the future are considered, although the vaccination strategies are still cost-effective up to 10 yearly boosters.

Changing the cervical cancer screening rates through pap smears affects the outcomes - increasing screening coverage rates increases ICER and decreases cost-benefit for vaccination due to the higher rates of early detection of CIN states which can be treated before they develop cancer. Increasing screening coverage also decreases the cost per life year saved for the bivalent vaccine compared to the quadrivalent vaccine because screening reduces $\mathrm{CIN}$ cases and therefore the advantage that the quadrivalent vaccine has in reducing the number of CIN cases due to non-oncogenic HPV.

The ICER for the quadrivalent vaccine vs. no vaccine increases with reduced effectiveness of the quadrivalent vaccine against genital warts. At $100 \%$ effectiveness the quadrivalent vaccine vs. no vaccine is more cost-effective compared to the bivalent vaccine vs. no vaccine across all 3 measures. Changing the sensitivity of the pap-smear tests, the compliance to treatment, or the cost of the interventions does not change the outcome substantially - vaccination remains cost-effective and the bivalent vaccine remains the more cost-beneficial strategy compared to the quadrivalent vaccine, and more-cost effective per life year saved. However, when using cost-per QALY saved, the quadrivalent vaccine dominates the bivalent vaccine across the board due to the additional QALYs saved from reducing genital warts.

The results of the one-way sensitivity analysis on ICER are shown in Figures 3 and 4. It is evident that the primary outcome is most affected by the vaccine effectiveness and the percentage of vaccine coverage. This means that vaccine parameters are the most important factors in the overall outcomes. The probability of

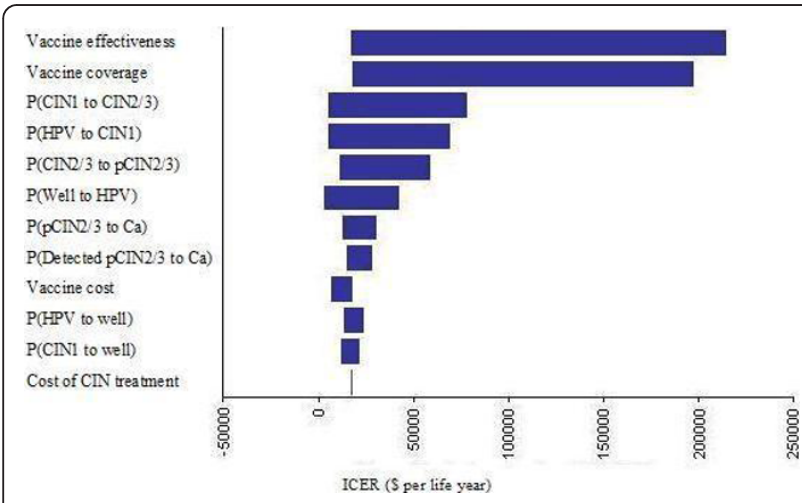

Figure 3 One-way sensitivity analysis tornado diagrams for the quadrivalent vaccine

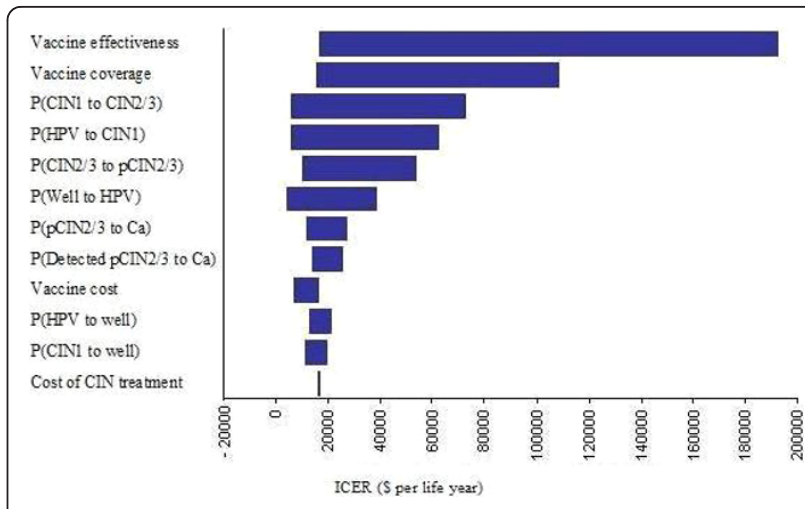

Figure 4 One-way sensitivity analysis tornado diagrams for the bivalent vaccine

infection with HPV, the probability of conversion from HPV to CIN1, and the transition probabilities between the CIN states and back to the well state also have some impact on the outcome. This is likely due to the importance of these parameters on the number of CIN cases that require treatment, and the eventual number of cancer cases. This also means that prevention of HPV infection and CIN is important to reduce the impact from the disease.

\section{Discussion}

During the last few decades, cervical cytology programmes have demonstrated their usefulness in reducing cervical cancer mortality and morbidity in many developed countries. However, it is a well-established fact that to be successful in population-based cervical screening, the coverage of the population screened must be adequate and this has often proved difficult to achieve. Although the incidence has declined over the years, cervical cancer, which is a preventable cancer, is still a common gynecological cancer in Singapore. With the global arrival of HPV vaccines, vaccination may be a successful complement to screening and decision on adoption of HPV vaccination will need to be made across individual countries.

The results of this study conclusively shows that HPV vaccination is a cost effective strategy at the population level, as the ICERs across most vaccination strategies were much lower than the per-capita GDP for Singapore, and the vaccine strategies were more cost-beneficial under a wide range of circumstances. This is similar to a recent study in Taiwan which showed the cost-effectiveness of universal vaccination of adolescent girls [51].

As a base case, the cost per life year saved for the bivalent vaccine was slightly lower compared to the quadrivalent vaccine, and the cost-benefit higher. At the same time, the cost per QALY saved is slightly lower for 
the quadrivalent vaccine compared to the bivalent vaccine. This is because the quadrivalent vaccine resulted in benefits from reduction in genital warts and CIN, but the bivalent vaccine increased life-years saved. Policy makers will therefore have to consider these factors (higher reduction in QALY versus more lives saved) in choosing between the 2 vaccines, but either option is much better than no vaccination at all.

The bivalent vaccine is most cost-beneficial at higher vaccine coverage rates of $>40 \%$, while the quadrivalent vaccine is more cost-effective and cost-beneficial at lower coverage rates as the number of lives saved are reduced. The quadrivalent vaccine also dominates the bivalent vaccine in the absence of cross-reactivity against non-16/18 oncogenic HPV types, due to the additional reduction on genital warts. This is similar to another study in Ireland which shows that the quadrivalent vaccine was more cost-effective assuming both vaccines have similarly high protective efficacy against HPV [29].

Of interest, if vaccine purchases are a priori and are sunk costs, the ICER increases substantially for both vaccines as vaccine coverage decreases, and cost-benefit decreases. Under this assumption, vaccine coverage of $\leq 40 \%$ would render vaccination not cost-effectiveness as an overall strategy. It is therefore important for policy makers rolling out universal vaccination strategies with stockpiled vaccines to ensure sufficient vaccine uptake to maintain high societal economic benefit, or to purchase vaccines on an as required basis based on vaccination uptake.

In addition, the waning of immunity and additional vaccinations contribute substantial to the vaccination costs. Boosters at intervals of once every 20 years still maintain the cost-effectiveness of vaccination. However, more frequent boosters of less than 10 years render vaccination a non-cost-effective strategy. Waning of immunity results in costs far greater compared to the absence of cross-protection to non-16/18 oncogenic HPV types or to genital warts. It is therefore more important for vaccine manufacturers to increase the efficacy of their vaccines in terms of long-term immunity.

This study does not take into account the dynamics of viral transmission and thus underestimating the impact of herd immunity. Transmission models that accounted for herd immunity suggest that vaccination and screening strategy would be much more attractive compared to screening-only - Chesson et al [9] further demonstrated that herd immunity could reduce ICER by $37.9 \%$. In addition, women who adhere to previous cervical screening tests may have better compliance with subsequent tests, but with the lack of information in the local context, we did not perform individual-based modelling. Also, the model does not take into consideration the potential reduction of other HPV-related cancers like adenocarcinoma of the cervix, vulvar carcinoma or laryngeal papillomatosis. Indirect costs such as absence of work or transportation costs for patients with cervical cancer are also excluded. Given that this study did not include herd immunity effects, we did not study the outcomes of vaccinating boys or optimal catch-up strategies, and we did not consider catch up vaccination, which could increase the immediate benefits of vaccination programs.

\section{Conclusions}

We demonstrate that vaccination of adolescent girls, in addition to current cytology-based screening, is a costeffective use of healthcare resources. The bivalent vaccine saves more lives compared to the quadrivalent vaccine, while the quadrivalent vaccine has lower cost per QALYs saved compared to the bivalent vaccine. The main advantage of vaccination will be to reduce cervical cancer mortality but the full benefits of vaccination will be observed 10-20 years after its introduction. Further studies should focus on quantifying the duration of vaccine protection, and use dynamic models to examine the efficiencies of different screening and vaccine strategies in reducing HPV-related disease. Studies should also focus on optimal synergies between screening and vaccination and on affordability and equity in delivery.

\section{Author details}

${ }^{1}$ Center for Health Services Research, National University of Singapore, Singapore. ${ }^{2}$ Department of Epidemiology and Public Health, National University of Singapore, Singapore. ${ }^{3}$ Department of Obstetrics \&

Gynaecology, Singapore General Hospital, Singapore. ${ }^{4}$ GlaxoSmithKline Biologicals, Singapore.

\section{Authors' contributions}

VJL and TMY conceived the study, collected the data, performed the analysis, and wrote the first draft of the manuscript together. SKT conceived the study, collected the data, and wrote the manuscript. YLT conceived the study, collected the data, and wrote the manuscript. All authors have read and approved the final manuscript.

\section{Competing interests}

This study was funded by a research grant from GSK Biologicals. VJL, SKT, and TMY have received research funding from GSK.

Received: 26 July 2010 Accepted: 31 March 2011

Published: 31 March 2011

\section{References}

1. Parkin DM, Bray F, Ferlay J, Pisani P: Golbal cancer statistics, 2002. CA Cancer J Clin 2005, 55: 74-108.

2. World Health Organization (WHO): Projections of mortality and burden of disease [http://www.who.int/healthinfo/global_burden_disease/projections/ en/index.html], [Accessed 29th July 2009].

3. Tay SK, Ngan HY, Chu TY, Cheung AN, Tay EH: Epidemiology of human papillomavirus infection and cervical cancer and future perspectives in Hong Kong, Singapore and Taiwan. Vaccine 2008, 26(Suppl 12): M60-70.

4. Health Promotion Board: Singapore. Health Programmes - Cervical Screen Singapore [http://www.hpb.gov.sg/hpb/default.asp?pg_id=1741], [Accessed 27th July 2009].

5. Munoz N, Boasch FX, de Sanjose S, et al: Epidemiologic Classification of Human Papillomavirus Types Associated with Cervical Cancer. N Engl J Med 2003, 348: 518-27. 
6. Burd EM: Human papillomavirus and cervical cancer. Clin Microbiol Rev 2003, 16: 1-17.

7. Clifford GM, Smith JS, Aguado T, et al: Comparison of HPV type distribution in high-grade cervical lesions and cervical cancer: a metaanalysis. Br J Cancer 2003, 89: 101-5.

8. Techakehakij W, Feldman RD: Cost-effectiveness of HPV vaccination compared with PAP smear screening on a national scale: a literature review. Vaccine 2008, 26(49): 6258-6265.

9. Chesson HW, Ekwueme DU, Saraiya M, Markowtiz LE: Cost-effectiveness of human papillomavirus vaccination in the United States. Emerg Infect Dis 2008, 14: 244-51.

10. Goldie SJ, Kohli M, Grima D, et al: Projected clinical benefits and costeffectiveness of a human papillomavirus 16/18 vaccine. J Natl Cancer Inst 2004, 96(8): 604-615.

11. Kim JJ, Goldie SJ: Health and economic implications of HPV vaccination in the United States. New England Journal of Medicine 2008, 359(8): 821-832.

12. Brisson M, Van de Valde N, De Wals P, Boily MC: Potential costeffectiveness of prophylactic human papillomavirus vaccines in Canada. Vaccine 2007, 25(29): 5399-408.

13. Kulasingam SL, Benard S, Barnabas RV, Largeron N, Myers ER: Adding a quadrivalent human papillomavirus vaccine to the UK cervical cance screening programme: a cost-effectiveness analysis. Cost Effectiveness and Resource Allocation 2008, 6: 4 .

14. Dasbach EJ, Insinga RP, Elbasha EH: The epidemiological and economic impact of a quadrivalent human papillomavirus vaccine (6/11/16/18) in the UK. BJOG: an International Journal of Obstetrics and Gynaecology 2008, 115(8): 947-956.

15. Jit $\mathrm{M}$, Choi $\mathrm{YH}$, Edmunds WJ: Economic evaluation of human papillomavirus vaccination in the United Kingdom. BMJ 2008, 337: a769.

16. Szucs TD, Largeron N, Dedes KJ, Rafia R, Benard S: Cost-effectiveness analysis of adding a quadrivalent HPV vaccine to the cervical cancer screening programme in Switzerland. Curr Med Res Opin 2008, 24(5): 1473-83, May.

17. Kim JJ, Kobus KE, Diaz M, et al: Exploring the cost-effectiveness of HPV vaccination in Vietnam: insights for evidence-based cervical cancer prevention policy. Vaccine 2008, 26(32): 4015-4024.

18. Dasbach EJ, Elbasha EH, Insinga RP: Mathematical models for predicting the epidemiologic and economic impact of vaccination against human papillomavirus infection and disease. Epidemiol Rev 2006, 28: 99-100.

19. Elbasha EH, Dasbach EJ, Insinga RP: Model of assessing human papillomavirus vaccination strategies. Emerg Infect Dis 2007, 13(1): 28-41.

20. Singapore Department of Statistics: Complete Life Tables 2006-2008 for Singapore Resident Population [http://www.singstat.gov.sg/pubn/popn/ lifetable06-09.pdf], [online]. [Accessed 15th April 2011].

21. Kohli M, Ferko N, Martin A, Franco EL, Jenkins D, Gallivan S, et al: Estimating the long-term impact of a prophylactic human papillomavirus $16 / 18$ vaccine on the burden of cervical cancer in the UK. Br J Cancer 2007, 96(1): 143-50.

22. Kulasingam S, Connelly L, Conway E, Hocking JS, Myers E, Regan DG, Roder D, Ross J, Wain G: A cost-effectiveness analysis of adding a human papillomavirus vaccine to the Australian. National Cervical Cancer Screening Program. Sexual Health 2007, 4: 165-175.

23. Paavonen J, Naup P, Salmeon J, Wheeler CM, Chow SN, Apter D, et al: Efficacy of human papillomavirus (HPV)-16/18 AS04-adjuvanted vaccine against cervical infection and precancer caused by oncogenic HPV types (PATRICIA): final analysis of a double-blind, randomised study in young women. Lancet 2009, 374(9686): 301-314.

24. Rogoza RM, Ferko N, Bentley J, et al: Optimization of primary and secondary cervical cancer prevention strategies in an era of cervical cancer vaccination: a multi-regional health economic analysis. Vaccine 2008, 26S: F46-F58.

25. Debicki D, Ferko N, Demarteau N, Gallivan S, Bauch CT, Anonychuk A, et al: Comparison of detailed and succinct cohort modeling approaches in the evaluation of cervical cancer vaccination. Vaccine 2008, 26S: F16-F28.

26. Suárez E, Smith JS, Bosch FX, et al: Cost-effectiveness of vaccination against cervical cancer: a multi-regional analysis assessing the impact of vaccine characteristics and alternative vaccination scenarios. Vaccine 2008, 26S: F29-F45
27. FUTURE I/II Study Group: Four year efficacy of prophylactic human papillomavirus quadrivalent vaccine against low grade cervical, vulvar, and vaginal intraepithelial neoplasia and anogenital warts: randomised controlled trial. BMJ 2010, 341: c3493.

28. Villa LL, Costa RL, Petta CA, Andrade RP, Paavonen J, Iversen OE, et al: High sustained efficacy of a prophylactic quadrivalent human papillomavirus types 6/11/16/18 L1 virus-like particle vaccine through 5 years of followup. Br J Cancer 2006, 95(11): 1459-66.

29. Dee A, Howell F: A cost-utility analysis of adding a bivalent or quadrivalent HPV vaccine to the Irish cervical screening programme. Eur J Public Health 2010, 20(2): 213-9.

30. Cuzick J, Szarewski A, Terry G, Ho L, et al: Human papillomavirus testing in primary cervical screening. Lancet 1995, 345(8964): 1533-6.

31. Fahey MT, Irwig L, Macaskill P: Meta-analysis of Pap test accuracy. Am J Epidemiol 1995, 141(7): 680-689.

32. Brown DR, Kjaer SK, Sigurdsson $K$, Iversen $\mathrm{OE}$, et al: The impact of quadrivalent human papillomavirus (HPV; types 6, 11, 16, and 18) L1 virus-like particle vaccine on infection and disease due to oncogenic nonvaccine HPV types in generally HPV-naive women aged $16-26$ years. J Infect Dis 2009, 199(7): 926-35.

33. Skinner SR, et al: Cross-protective efficacy of The bivalent vaccine ${ }^{T M}$ against oncogenic HPV types beyond HPV-16/18. Abstract presented at the 25th International Papillomavirus Conference (IPV) Malmo, Sweden; 2009.

34. Brown DR, Fife KH, Wheeler CM, Koutsky LA, et al: Early assessment of the efficacy of a human papillomavirus type $16 \mathrm{~L} 1$ virus-like particle vaccine. Vaccine 2004, 22(21-22): 2936-42.

35. Harper DM, Franco EL, Wheeler CM, Moscicki AB, Romanowski B, RoteliMartins CM, et al: Sustained efficacy up to 4.5 years of a bivalent L1virus-like particle vaccine against human papillomavirus types 16 and 18: follow-up from a randomized controlled trial. Lancet 2006, 367(9518): $1247-55$.

36. Koutsky LA, Ault KA, Wheeler CM, Brown DR, Barr E, Alvarez FB, et al: A controlled trial of human papillomavirus type 16 vaccine. $N$ Engl $J$ Med 2002, 347(21): 1645-51.

37. Mao C, Koutsky LA, Ault KA, Wheeler CM, Brown DR, Wiley DJ, et al: Efficacy of human papillomavirus-16 vaccine to prevent cervical intraepithelial neoplasia: a randomized controlled trial. Obstet Gynecol 2006, 107(1): 18-27.

38. Villa LL, Ault KA, Giuliano AR, Costa RL, Petta CA, Andrade RP, et al: Immunologic responses following administration of a vaccine targeting human papillomavirus types 6, 11, 16 and 18. Vaccine 2006, 24(27-28): 5571-83.

39. Paavonen J, Jenkins D, Bosch X, Naud P, Salmeron J, Wheeler CM: Efficacy of a prophylactic adjuvanted bivalent $\mathrm{L} 1$ virus-like-particle vaccine against infection with HPV types 16 and 18 in young women: an interim analysis of a phase III double-blind randomized controlled trial. Lancet 2007, 369(9580): 2161-70.

40. The FUTURE II Study Group: Quadrivalent vaccine against HPV to prevent highgrade lesions. N Engl J Med 2007, 356(19): 1915-27.

41. Health Promotion Board: Abnormal Pap Smear \& Preinvasive Disease of the Cervix. Health Promotion Board, Singapore 2002.

42. Wang H, Chia KS, Du WB, et al: Population-based survival for cervical cancer in Singapore, 1968-1992. Am J Obstet Gynecol 2003, 188: 324-9.

43. Von Krogh G, Lacey CJ, Gross G, et al: European course on HPV associated pathology: guidelines for primary case physicians for the diagnosis and management of anogenital warts. Sex Transm Infect 2000, 76: 162-8.

44. Fairley CK, Donovan B: What can surveillance of genital warts tell us? Sex Health 2010, 7(3): 325-7.

45. Goldie SJ, Kohli M, Grima D, et al: Projected clinical benefits and costeffectiveness of a human papillomavirus 16/18 vaccine. J Natl Cancer Inst 2004, 96(8): 604-615.

46. Hay J, Jackson J: Methodological Issues in Conducting Pharmacoeconomic Evaluations-Modeling Studies. Value in Health 1999, 2(No. 3): 78-81.

47. Bonneux L, Birnie $E$ : The discount rate in the economic evaluation of prevention: a thought experiment. J Epidemiol Community Health 2001, 55(2): 123-5.

48. Bos JM, Postma MJ, Annemans L: Disconting health effects in pharmacoeconomic evaluations: current controversies. Pharmacoeconomics 2005, 23(7): 639-49.

49. Torgenson DJ, Raftery L: Economic notes. Discounting. BMJ 1999, 319(7214): 914-5. 
50. Haddix AC, Teutsh SM, Corso PS: Prevention Effectiveness- A Guide to Decision Analysis and Economic Evaluation. New York: Oxford University Press; 2 2003, 18.

51. Liu PH, Hu FC, Lee PI, Chow SN, Huang CW, Wang JD: Cost-effectiveness of human papillomavirus vaccination for prevention of cervical cancer in Taiwan. BMC Health Serv Res 2010, 10: 11.

\section{Pre-publication history}

The pre-publication history for this paper can be accessed here: http://www.biomedcentral.com/1471-2458/11/203/prepub

doi:10.1186/1471-2458-11-203

Cite this article as: Lee et al: Cost-effectiveness of different human papillomavirus vaccines in Singapore. BMC Public Health 2011 11:203.

\section{Submit your next manuscript to BioMed Central} and take full advantage of:

- Convenient online submission

- Thorough peer review

- No space constraints or color figure charges

- Immediate publication on acceptance

- Inclusion in PubMed, CAS, Scopus and Google Scholar

- Research which is freely available for redistribution

Submit your manuscript a www.biomedcentral.com/submit 